\title{
A neutron diffraction investigation of high valent doped barium ferrite with wideband tunable microwave absorption
}

\author{
Jun $\mathrm{LI}^{a, b,{ }^{*},}$, Yang $\mathrm{HONG}^{c, \dagger}$, San $\mathrm{HE}^{a, b}$, Weike $\mathrm{LI}^{a, b}$, Han $\mathrm{BAI}^{a, b}$, \\ Yuanhua XIA ${ }^{d}$, Guangai $\mathrm{SUN}^{d}$, Zhongxiang ZHOU ${ }^{a, b, *}$ \\ ${ }^{a}$ School of Physics, Harbin Institute of Technology, Harbin 150001, China \\ ${ }^{b}$ Heilongjiang Provincial Key Laboratory of Plasma Physics and Application Technology, \\ Harbin Institute of Technology, Harbin 150001, China \\ ${ }^{c}$ School of Chemistry and Chemical Engineering, Harbin Institute of Technology, Harbin 150001, China \\ ${ }^{d}$ Key Laboratory for Neutron Physics of CAEP, Institute of Nuclear Physics and Chemistry, Mianyang 621999, China
}

Received: January 30, 2021; Revised: August 20, 2021; Accepted: August 21, 2021

(c) The Author(s) 2021.

\begin{abstract}
The barium ferrite $\mathrm{BaTi}_{x} \mathrm{Fe}_{12-x} \mathrm{O}_{19}(x=0.2,0.4,0.6,0.8)$ (BFTO- $\left.x\right)$ ceramics doped by $\mathrm{Ti}^{4+}$ were synthesized by a modified sol-gel method. The crystal structure and magnetic structure of the samples were determined by neutron diffraction, and confirm that the BFTO- $x$ ceramics were high quality single phase with sheet microstructure. With $x$ increasing from 0.2 to 0.8 , the saturation magnetization $\left(M_{\mathrm{s}}\right)$ decreases gradually but the change trend of coercivity $\left(H_{\mathrm{c}}\right)$ is complex under the synergy of the changed grain size and the magnetic crystal anisotropy field. Relying on the high valence of $\mathrm{Ti}^{4+}$, double resonance peaks are obtained in the curves of the imaginary part of magnetic conductivity $\left(\mu^{\prime \prime}\right)$ and the resonance peaks could move toward the low frequency with the increase of $x$, which facilitate the samples perform an excellent wideband modulation microwave absorption property. In the $x=0.2$ sample, the maximum reflection loss (RL) can reach $-44.9 \mathrm{~dB}$ at the thickness of only $1.8 \mathrm{~mm}$, and the bandwidth could reach $5.28 \mathrm{GHz}$ at $2 \mathrm{~mm}$ when RL is less than $-10 \mathrm{~dB}$. All the BFTO- $x$ ceramics show excellent frequency modulation ability varying from $18(x=0.8)$ to $4 \mathrm{GHz}$ $(x=0.4)$, which covers $81 \%$ of the investigated frequency in microwave absorption field. This work not only implements the tunable of electromagnetic parameters but also broadens the application of high-performance microwave absorption devices.
\end{abstract}

Keywords: barium ferrite; neutron diffraction; microwave absorption

\section{Introduction}

The rapid development of electronic information

$\dagger$ Jun Li and Yang Hong contributed equally to this work.

* Corresponding authors.

E-mail: J. Li, lijuna@hit.edu.cn;

Z.Zhou, zhouzx@hit.edu.cn technology and communication industry has increased the requirements of microwave absorption materials to solve the uncovering electromagnetic interference problems [1-3]. Thus, developing microwave absorption materials of large reflection loss (RL) and broad bandwidth are becoming urgent. The inherent properties of microwave absorbing materials, including complex permeability and permittivity, are significant in enhancing 
RL and broadening the effective bandwidth [4-6].

The microwave absorption materials can be classified into a resistive type, a dielectric type, and a magnetic medium type according to the loss mechanism [7-9]. The resistive absorbing materials mainly absorb electromagnetic wave by interaction with an electric field, and the absorption efficiency depends on the conductivity and dielectric constant, include carbon black, metal powder, silicon carbide, graphite, and special carbon fiber [10]. For dielectric absorbing materials, the electromagnetic wave is mainly absorbed by the dielectric polarization relaxation loss, and the typical representative is barium titanate ferroelectric ceramics [11]. The attenuation of the electromagnetic wave by the magnetic medium type absorbing materials mainly comes from resonance and hysteresis loss, such as ferrite and carbonyl iron [12,13]. Among all these materials, the ferrite is an ideal microwave absorbing material for the simple preparation process and the stable performance [14-16].

M-type barium ferrite $\left(\mathrm{BaFe}_{12} \mathrm{O}_{19}\right.$, abbreviated as $\mathrm{BaM})$, a versatile material, performs excellent electromagnetic properties due to the large magnetic loss at the natural resonance frequency. Pure barium ferrite has large saturation magnetization $\left(M_{\mathrm{s}}\right)$, high coercivity, magnetic anisotropy constants, and the large magnetic loss at the natural resonance frequency, which make barium ferrite have excellent microwave absorption characteristics [17,18]. To investigate larger RL, broader bandwidth, and even tunable microwave absorbing material, many kinds of research work on barium ferrite doping modification are carried out $[19,20]$. The magnetic loss is related to the content of $\mathrm{Fe}^{3+}$ in barium ferrite, and thus the microwave absorption properties can be adjusted when $\mathrm{Fe}^{3+}$ ions are substituted with other trivalent ions or combination of divalent and tetravalent ions [21]. BaM-based cationic substitutions for $\mathrm{Fe}^{3+}$ are used to modify the dielectric and magnetic parameters, which play an important role in RL calculation. The substitutions for $\mathrm{Fe}^{3+}$ of BaM-based can be divided into two main approaches: covalent cation substitution, such as $\mathrm{Ga}^{3+}, \mathrm{In}^{3+}$; and $\mathrm{Er}^{3+}$ and hetervalent cationic combination, such as $\mathrm{Co}^{2+}-\mathrm{Ti}^{4+}, \mathrm{Co}^{2+}-\mathrm{Zr}^{4+}$, and $\mathrm{Ni}^{2+}-\mathrm{Ti}^{4+}$ [22-26]. However, recent studies have shown that the introduction of high-valence ions destroys the valence state equilibrium of barium ferrite, resulting in multiple absorption peaks, which can increase the bandwidth of electromagnetic wave absorption of the material [27-29].
In this work, we synthesized $\mathrm{BaFe}_{12-x} \mathrm{Ti}_{x} \mathrm{O}_{19}$ (BFTO- $x$, $x=0.2,0.4,0.6,0.8)$ using only tetravalent $\mathrm{Ti}^{4+}$ ions as high valent dopant ions by a modified sol-gel method. We systematically analyzed the structure, morphology, magnetic properties, and electromagnetic parameters of the sample. By comparing the magnetic structure of the neutron diffraction with the experimental magnetic results, the internal magnetic mechanism of the sample was deeply studied. The modified M-type barium ferrite exhibits better tunability for electromagnetic properties, which has a positive role on the exploration of the novel microwave absorbing materials.

\section{Experimental}

\section{1 Material synthesis}

The $\mathrm{Ti}^{4+}$ doped M-type barium ferrite ceramics $\left(\mathrm{BaFe}_{12-x} \mathrm{Ti}_{x} \mathrm{O}_{19}, x=0.2,0.4,0.6,0.8\right)$ were prepared utilizing the modified sol-gel method that is more effective than conventional solid state method. Barium nitrate $\left(\mathrm{Ba}\left(\mathrm{NO}_{3}\right)_{2}\right)$, iron nitrate $\left(\mathrm{Fe}\left(\mathrm{No}_{3}\right)_{3} \cdot 9 \mathrm{H}_{2} \mathrm{O}\right)$, and titanium nitrate $\left(\mathrm{Ti}\left(\mathrm{NO}_{3}\right)_{4}\right)$ were weighted in a stoichiometric ratio and dissolved in citric acid solution adequately. The $\mathrm{pH}$ value of the solution was adjusted to 8 by adding ammonia water, and then the solution was stirred for $2 \mathrm{~h}$ and aged for $12 \mathrm{~h}$ at room temperature. The mixed solution was placed in $80{ }^{\circ} \mathrm{C}$ water bath for $3 \mathrm{~h}$ to form a sol, which was then transferred to a dry box at $120{ }^{\circ} \mathrm{C}$ for $1-2$ days until a dry gel was formed. The aerogel was incubated at $210{ }^{\circ} \mathrm{C}$ for $3 \mathrm{~h}$ to remove organic components from the gel. Calcination was carried out at $1200{ }^{\circ} \mathrm{C}$ to get the BFTO- $x$ powder. The powder mixed with polyvinyl alcohol (PVA) was pressed into wafers of $13 \mathrm{~mm}$ in diameter and sintered at $600{ }^{\circ} \mathrm{C}$ for $4 \mathrm{~h}$ to eliminate the binder, and then the wafers were sintered at $1200{ }^{\circ} \mathrm{C}$ for $4 \mathrm{~h}$ in air atmosphere to obtain the BFTO- $x$ ceramics.

\section{2 Characterizations}

The neutron powder diffraction (NPD) experiments were carried out at room temperature using the high resolution neutron powder diffractometer (HRND) $(\lambda=$ $1.884 \AA)$ at China Mianyang Research Reactor (CMRR), and the corresponding Rietveld refinement was achieved by FullProf and the simulated annealing and representational analysis (SARAh). Morphologies were examined using the field emission scanning electron microscopy (SEM; ZEISS Merlin Compact). 
Magnetic properties were investigated using a vibrating sample magnetometer (VSM, Lake Shore 7404). The electromagnetic properties were studied using the air-line method, which were mixed with PVA at a mass ratio of $6: 1$. The complex permittivity and permeability were measured through the coaxial method from 2 to $18 \mathrm{GHz}$ on a vector network analyzer (Keysight Technologies N5234A), and the sample and paraffin were mixed at a mass ratio of 7:3 and then compressed into a test ring with an outer diameter of $7 \mathrm{~mm}$ and an inner diameter of $3 \mathrm{~mm}$.

\section{Results and discussion}

\section{1 Effects of titanium substitution on crystal structure and microstructure}

The neutron diffraction patterns of BFTO- $x(x=0.2$, $0.4,0.6,0.8)$ ceramics are shown in Fig. 1(a), which contains the complete neutron diffraction pattern before and after refinement using Rietveld method. Since the neutron diffraction patterns include both structural and magnetic information, the process of BFTO- $x$ refinement using FullProf can be divided into two parts: structural and magnetic phases [30]. The detailed results of refinement contained structural and magnetic parameters also appear in Fig. 1(a), and the corresponding refinement factors of each components are also shown in Fig. 1(a). Compared with the neutron diffraction Bragg positions of pure barium ferrite, no other impurity peaks were found, indicating that the four components were single phase with space group $P 63 / m m c$. Moreover, the corresponding magnetic space group of BFTO- $x$ is $R-3 m: H$, which was determined by utilizing the SARAh Analysis to calculate the possible magnetic space groups [31]. The result of structural refinement shows that the lattice parameters change little with the increasing of Ti doping, and the corresponding parameters are $x=0.2(a=b=5.8946 \AA$, $c=23.2225 \AA), x=0.4(a=b=5.8940 \AA, c=23.2354 \AA)$, $x=0.6(a=b=5.8942533 \AA, c=23.2402 \AA)$, and $x=$ $0.8(a=b=5.8944 \AA, c=23.2361 \AA)$. The change may origin from that $\mathrm{Ti}$ ion occupies the position of $\mathrm{Fe}$ ion in the sublattice, and the atomic radius of $\mathrm{Ti}^{4+}$ ion $(0.0605 \mathrm{~nm})$ is basically the same with that of $\mathrm{Fe}^{3+}$ ion $(0.0645 \mathrm{~nm})$. The distortion of lattice structure stems from the replacement of $\mathrm{Ti}$ ions, leading to the concomitant changed of cell parameters. Another parameter characterizing the crystal and magnetic structure is the Bragg position. The structure of Bragg position has not changed with the Ti doping, which is corresponded with the refinement result of lattice parameters. However, the magnetic Bragg position changes with the increase of $\mathrm{Ti}$ doping. With the increase of $\mathrm{Ti}$, in order to keep the valence conserve, part of $\mathrm{Fe}^{3+}$ ions converted into $\mathrm{Fe}^{2+}$ ions, generating new Hollande factor. Therefore, new Bragg position generated when $x=0.6$. In addition, more analyses about structure are shown in Fig. S1 in the Electronic Supplementary Material (ESM).

Figure 1(b) shows that the primitive cell of $\mathrm{BaFe}_{12} \mathrm{O}_{19}$ is composed of $10 \mathrm{O}^{2-}$ ion layers, because the radii of $\mathrm{Ba}^{2+}$ ion $(0.142 \mathrm{~nm})$ and $\mathrm{O}^{2-}$ ion $(0.140 \mathrm{~nm})$ are not much different, and $\mathrm{Ba}^{2+}$ ion often occupies the

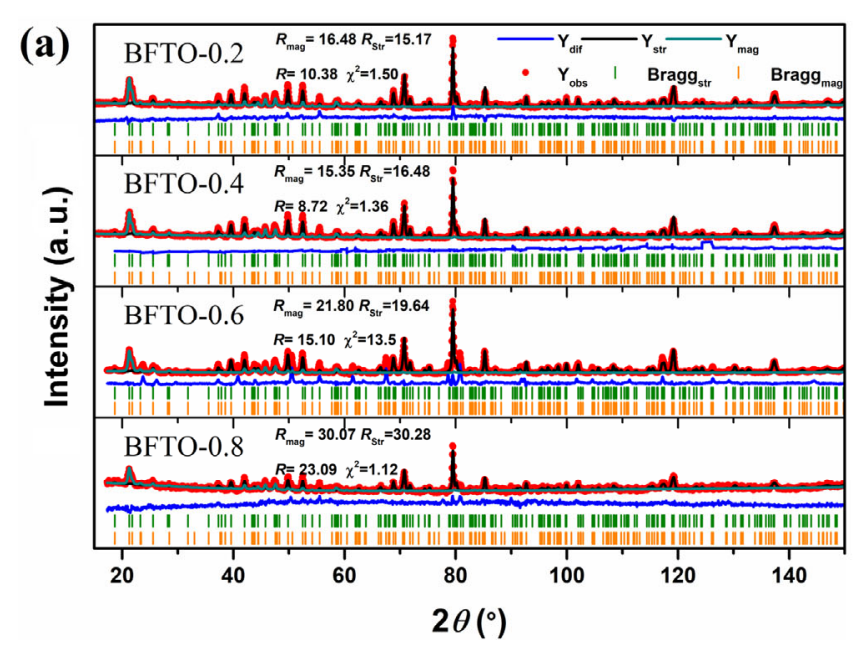

(b)

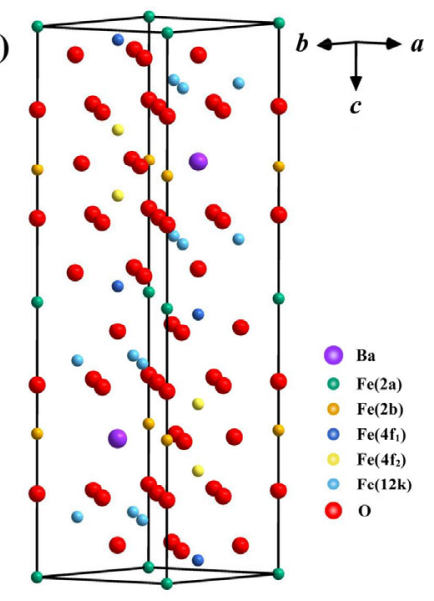

Fig. 1 (a) Neutron diffraction and corresponding refinement patterns of BFTO- $x(x=0.2,0.4,0.6,0.8)$ ceramics and (b) schematic structure of $\mathrm{BaFe}_{12} \mathrm{O}_{19}$. 
position of $\mathrm{O}^{2-}$ ion in the oxygen lattice of the crystal. Therefore, certain amounts of barium ions are contained in the close-packed structure of oxygen ions. Meanwhile, $\mathrm{Fe}^{3+}$ ions exist in the interstices of oxygen ions, forming a stable hexahedral structure. $\mathrm{Fe}^{3+}$ ions are distributed over five different positions in $\mathrm{BaFe}_{12} \mathrm{O}_{19}$, named $12 \mathrm{k}, 2 \mathrm{a}, 2 \mathrm{~b}, 4 \mathrm{f}_{1}$, and $4 \mathrm{f}_{2}$ [32]. Magnetic moment orientations of $\mathrm{Fe}^{3+}$ in three positions $(12 \mathrm{k}, 2 \mathrm{a}, 2 \mathrm{~b})$ spin up while those of $4 f_{1}$ and $4 f_{2}$ positions spin down. In order to obtain the information of exact occupation of $\mathrm{Ti}$, the method of neutron diffraction intensity fitting was utilized to explore the occupation probability of $\mathrm{Ti}$ as listed in Table 1. The result of fitting shows that $\mathrm{Ti}$ tends to occupy the position $2 \mathrm{a}, 2 \mathrm{~b}$, and $12 \mathrm{k}$, in where Fe is spin-up.

The surface morphologies of BFTO- $x$ ceramics are shown in Fig. 2. It can be observed that all components

Table 1 Occupation probability of BFTO- $x$ ceramics

\begin{tabular}{ccccc}
\hline & $x=0.2$ & $x=0.4$ & $x=0.6$ & $x=0.8$ \\
\hline $2 \mathrm{a}(\mathrm{Fe})$ & 0.08292 & 0.08290 & 0.08083 & 0.07965 \\
$2 \mathrm{a}(\mathrm{Ti})$ & 0.00041 & 0.00043 & 0.00250 & 0.00368 \\
$2 \mathrm{~b}(\mathrm{Fe})$ & 0.07125 & 0.05427 & 0.04083 & 0.02923 \\
$2 \mathrm{~b}(\mathrm{Ti})$ & 0.01208 & 0.02906 & 0.04250 & 0.05410 \\
$12 \mathrm{k}(\mathrm{Fe})$ & 0.49582 & 0.49830 & 0.49500 & 0.49114 \\
$12 \mathrm{k}(\mathrm{Ti})$ & 0.00417 & 0.00170 & 0.00500 & 0.00860 \\
\hline
\end{tabular}
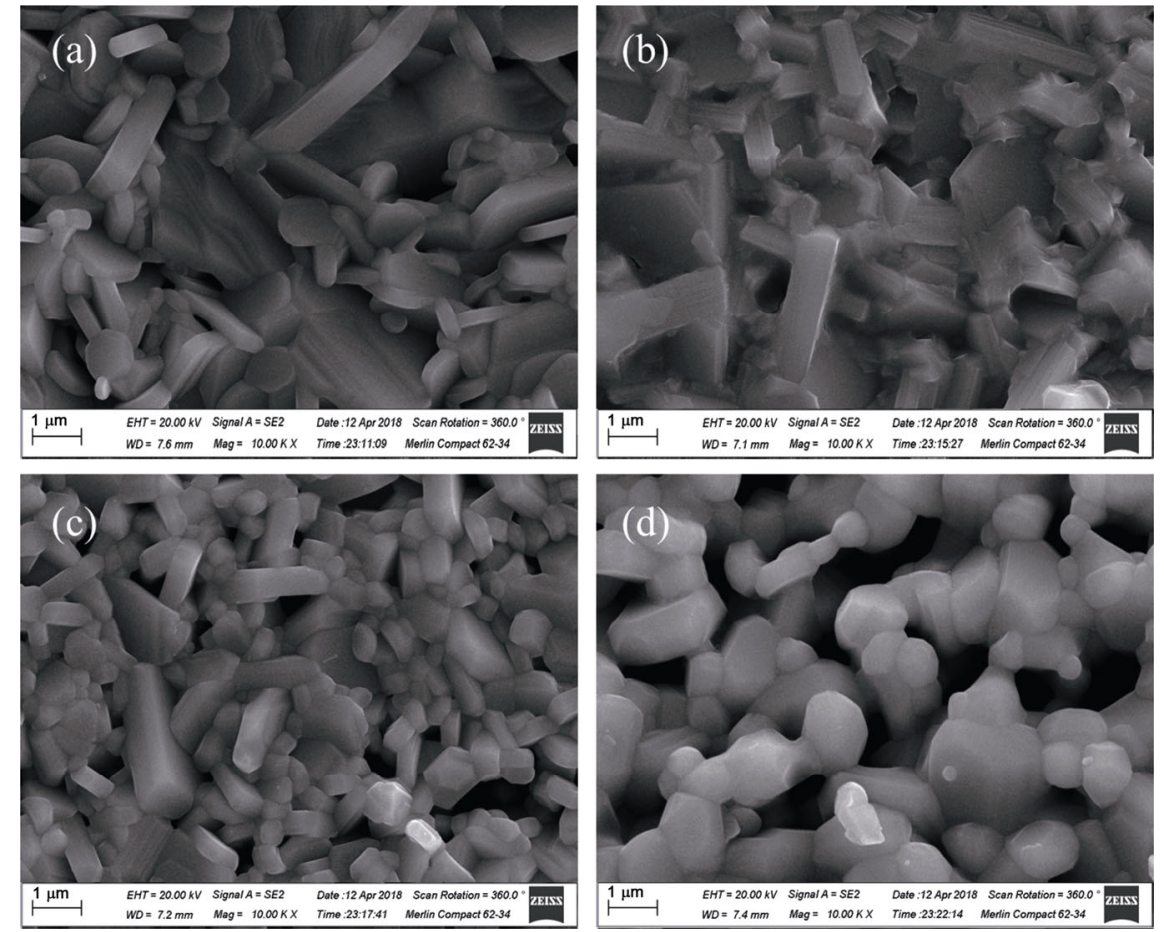

Fig. 2 SEM images of BFTO- $x$ ceramics with (a) $x=0.2$, (b) $x=0.4$, (c) $x=0.6$, and (d) $x=0.8$.

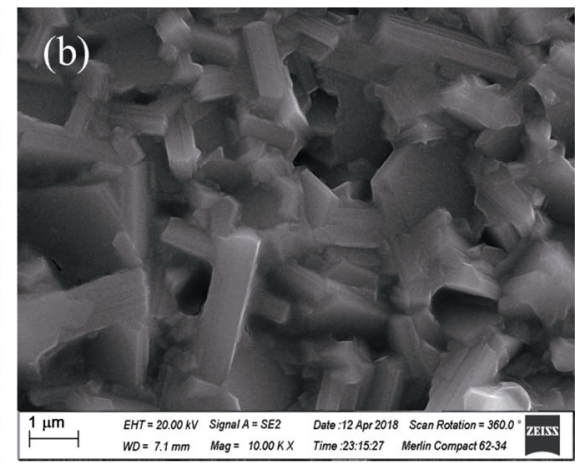

perform typical hexagonal plates, and the grain boundary is distinct. The particle size of BFTO- $x$ ceramics varies with the increase of $x$, where the grain size of BFTO- 0.4 about $1 \mu \mathrm{m}$ is larger than those of the other three components. Compared with the solid state sintering method, the grain size of BFTO ceramics prepared by the sol-gel process is smaller, which has an important effect on coercive force [33].

\section{2 Effects of titanium substitution on magnetic properties}

The magnetic properties of BFTO- $x(x=0.2,0.4,0.6$, $0.8)$ ceramics are derived from magnetic hysteresis loops at room temperature in Fig. 3. It can be seen that all samples are approaching saturation as the applied field is increased up to $15 \mathrm{kOe}$. With $x$ increasing from 0.2 to 0.8 , the $M_{\mathrm{s}}$ decreases gradually from 31.87 to $22.13 \mathrm{emu} / \mathrm{g}$, while the change trend of coercivity $\left(H_{\mathrm{c}}\right)$ is complicated. The change trend of $M_{\mathrm{s}}$ and $H_{\mathrm{c}}$ is related to the magnetic moment of $\mathrm{Fe}^{3+}$ and the occupied position during doping $[34,35]$.

The replacement from $\mathrm{Ti}^{4+}$ ion to the magnetic $\mathrm{Fe}^{3+}$ ion $(5 \mu \mathrm{B})$ would reduce the $M_{\mathrm{s}}$ of barium ferrite ceramics since the $\mathrm{Ti}^{4+}$ ion is non-magnetic, and $M_{\mathrm{s}}$ exhibits a downward trend with the increase of $\mathrm{Ti}^{4+}$ ion doping due to the decrease of super-exchange effect 


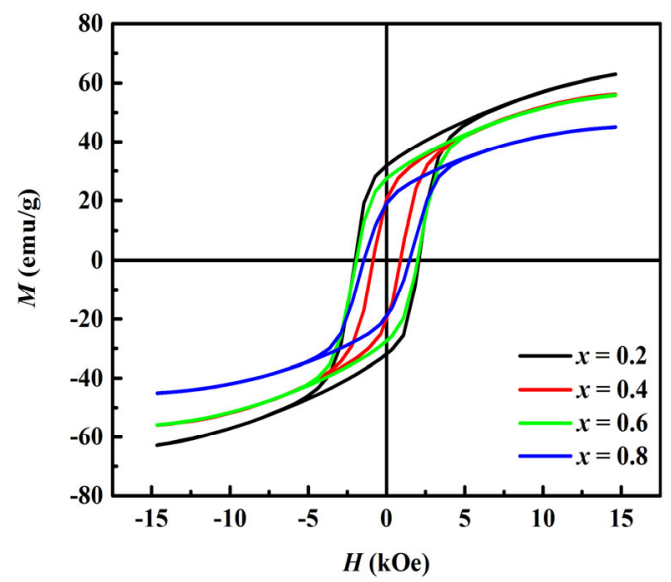

Fig. 3 Magnetic hysteresis loops $(M-H)$ of samples at room temperature.

between $\mathrm{Fe}^{3+}-\mathrm{O}_{2}-\mathrm{Fe}^{3+}$ [36]. It is known that $H_{\mathrm{c}}$ is mainly affected by anisotropic field $\left(H_{\mathrm{a}}\right)$ and grain size $[37,38]$. That is, the larger the grain size of ceramics, the smaller the $H_{\mathrm{c}}$. On the other hand, $H_{\mathrm{c}}$ is proportional to $H_{\mathrm{a}}$. According to the formula $H_{\mathrm{a}}=$ $2 K_{1} / M_{\mathrm{s}}, H_{\mathrm{a}}$ is proportional to the magnetic crystal anisotropy constant $\left(K_{1}\right)$, and inversely proportional to $M_{\mathrm{s}}[39,40]$. According to the contribution of different lattice positions to $K_{1}$, the $2 \mathrm{~b}$ position has the greatest effect on $K_{1}$. Therefore, the more components are doped, the greater the effect on $H_{\mathrm{c}}$. For the components $x=0.2,0.6$, and $0.8, H_{\mathrm{c}}$ has a is declining trend with the increase of the doping. Because the changes of the grain size and $M_{\mathrm{s}}$ are weak, the declining trend of the $H_{\mathrm{c}}$ is contributed to the influence of $K_{1}$. The reason for the sharp decline of $H_{\mathrm{c}}$ of BFTO-0.4 ceramic sample is relatively complex and can be attributed to two aspects $[41,42]$. Firstly, the SEM image of BFTO- $x$ ceramics shows that the grain size of BFTO- 0.4 ceramic sample is larger than that of other components, so the $H_{\mathrm{c}}$ of BFTO-0.4 ceramic will be smaller. Secondly, the increase of $\mathrm{Ti}^{4+}$ doping and the occupied position would have a greater influence on $K_{1}$, which also causes the obvious change of $H_{\mathrm{c}}$. However, compared to BFTO-0.2 ceramic sample, the $M_{\mathrm{s}}$ change of BFTO- 0.4 ceramic sample is smaller than that of BFTO-0.2. Therefore, the effect of $M_{\mathrm{s}}$ on $H_{\mathrm{c}}$ can be neglected, and the change of $H_{\mathrm{c}}$ mainly depends on the grain size and $K_{1}$.

Moreover, refined magnetic structure shows that non-collinear magnetic structure exists in BFTO- $x$ ceramics $[30,43]$. The magnetic moment of primitive cell varies with the doping content of $\mathrm{Ti}$, which is the same with experimental data, and the corresponding results are listed in Table 2. The experimental magnetic
Table 2 Magnetic moment of BFTO-x ceramics' primitive cell

\begin{tabular}{ccccc}
\hline & $x=0.2$ & $x=0.4$ & $x=0.6$ & $x=0.8$ \\
\hline Experimental $(\mu \mathrm{B})$ & 12.056 & 11.138 & 10.819 & 11.731 \\
Theoretical $(\mu \mathrm{B})$ & 17.167 & 14.421 & 11.907 & 14.231 \\
\hline
\end{tabular}

moment of primitive cell $\left(M_{\mathrm{pc}}\right)$ was calculated by Eq. (1):

$$
M_{\mathrm{pc}}(\mu \mathrm{B})=\frac{M_{\mathrm{s}}(\mathrm{emu} / \mathrm{g}) \times 1.0783 \times 10^{20}}{N_{\mathrm{A}}} \times M(\mathrm{BFTO}-x)(1)
$$

where $M(\mathrm{BFTO}-x)$ is the molar mass of BFTO- $x$ and $N_{\mathrm{A}}$ is the Avogadro constant. From the result of magnetic refinement, the theoretical $M_{\mathrm{pc}}$ fluctuates with the increase of Ti doping, which is consistent with the trend of experimental result.

\section{3 Effects of titanium substitution on electro- magnetic and microwave absorption properties}

The complex permittivity $\left(\varepsilon=\varepsilon^{\prime}-\mathrm{j} \varepsilon^{\prime \prime}\right)$ and complex permeability $\left(\mu=\mu^{\prime}-\mathrm{j} \mu^{\prime \prime}\right)$ of BFTO- $x$ ceramics are shown in Fig. 4 , which are measured by the air-line method within 2-18 GHz. As observed, the real part of permittivity $\varepsilon^{\prime}$ of $x=0.4$ component can reach 25 , while the $\varepsilon^{\prime}$ of the other components is smaller to some extent. For the imaginary part of permittivity $\varepsilon^{\prime \prime}$, there are remarkable dielectric relaxation phenomena in all samples, which can contribute to increasing RL of the absorbing sample. In Fig. 4(d), the apparent resonance phenomenon can be observed. It is necessary to note that the natural resonance frequency of the component $x=0.2$ is larger than $18 \mathrm{GHz}$, while the natural resonance frequency of the other three components at a frequency range of 6-14 GHz illustrated in the inset of Fig. 4(d) is within the measured frequency range.

According to the formula $f_{\mathrm{r}}=1.4 g H_{\mathrm{a}}$, the natural resonant frequency $\left(f_{\mathrm{r}}\right)$ is correlated with the magnetic $H_{\mathrm{a}}$ of the ceramic sample and the Hollande factor $(g)$ [44]. Due to the low $H_{\mathrm{a}}$ of BFTO- 0.4 ceramic, the natural resonant frequency of the $x=0.4$ sample is the lowest and appears near $8 \mathrm{GHz}$, while double resonance peaks were obtained in $x=0.6$ and $x=0.8$ components. The high-valence ionic $\mathrm{Ti}^{4+}$ doping, which destroys the valence equilibrium of barium ferrite, will produce a new $g$ factor, and the appearance of double resonance peaks shows that there are two $g$ factors in these samples. With the increase of $\mathrm{Ti}^{4+}$ doping, the $H_{\mathrm{a}}$ decreases, and the natural resonance frequency moves to the lower frequency range. Therefore, 

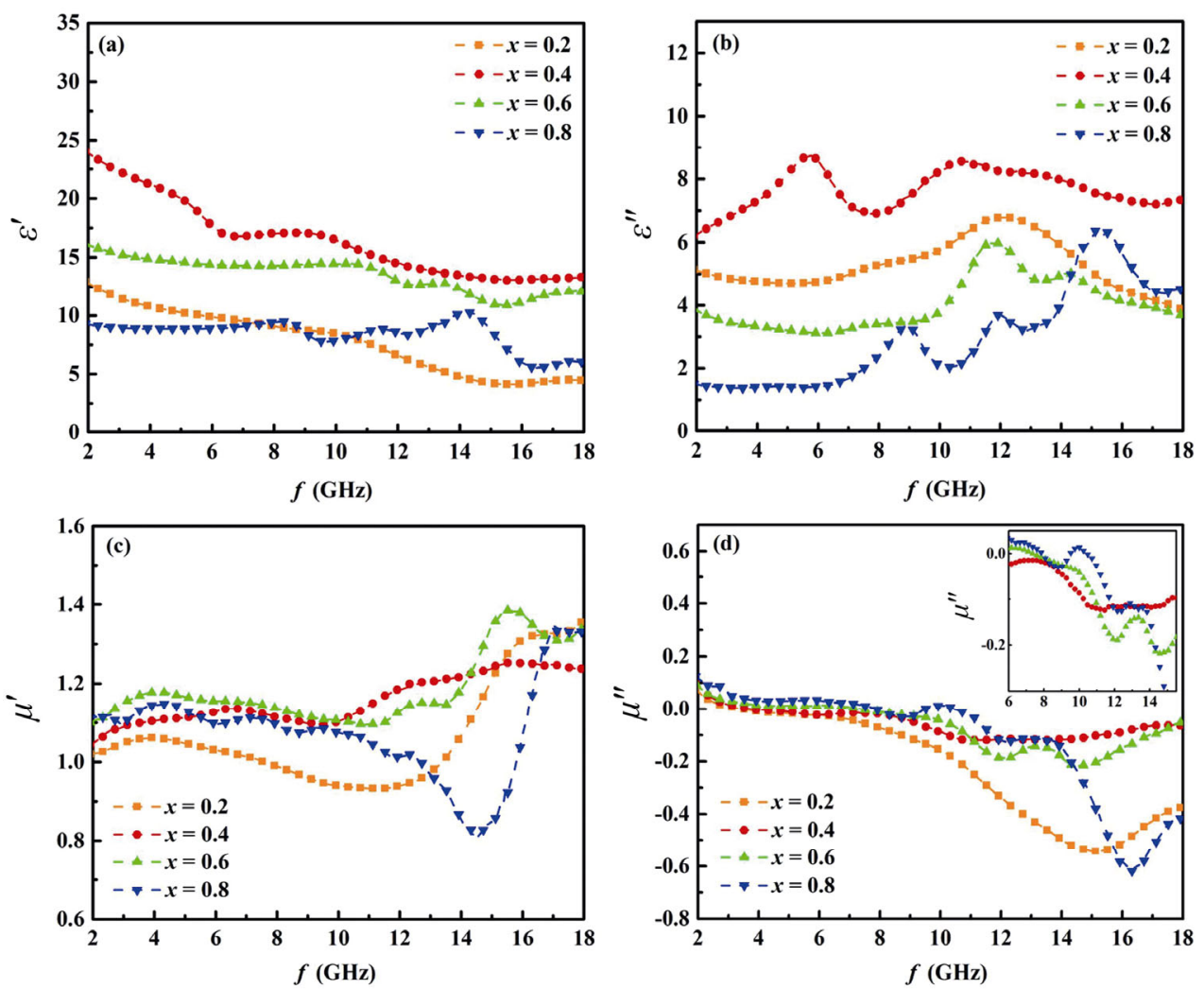

Fig. 4 Electromagnetic parameters of PVA mixed BFTO- $x$ ceramics: (a) real parts and (b) imaginary parts of the complex permittivity, and (c) real parts and (d) imaginary parts of the complex permeability.

the appearance of double resonance peak is advantageous to obtain the larger bandwidth. More evidence can be found in Fig. S2 in the ESM, which shows the dielectric and magnetic loss of PVA mixed BFTO- $x$ ceramics. The large dielectric and magnetic loss was obtained in the $x=0.2$ sample, which indicates a large RL. The loss curves of $x=0.6$ and 0.8 have evident fluctuation, and could get large bandwidth.

The RL of PVA mixed BFTO- $x$ ceramics can be calculated from the measured electromagnetic parameters [45], as shown in Fig. 5. Relying on the dielectric and magnetic loss, the four components of PVA mixed BFTO- $x$ ceramics have obtained a large RL. The maximum RL of $-44.9 \mathrm{~dB}$ means that the absorption of electromagnetic waves can reach $99.99 \%$ which was obtained in the $x=0.2$ sample, and the thickness is relatively thin, only $1.8 \mathrm{~mm}$. The absorption of electromagnetic waves can also reach $90 \%$ in the other three components. The apparent double absorption peaks appear in Figs. 5(c) and 5(d), which maybe origin from the presence of more than one of the Hollande factors in the wave-absorbing material that can benefit for widening the bandwidth of the material. $\mathrm{RL}$ and bandwidth are two important indexes to evaluate the performance of absorbing materials, and high-loss and large-bandwidth materials can be used in a wider range of applications [46].

Figure 6 shows the 3D RL contour plots of BFTO- $x$ ceramics, and all samples perform wide bandwidth in the specific frequency and thickness. Although the absorption of electromagnetic waves by this material is not the best, we can find that with the doping of $\mathrm{Ti}^{4+}$ ions, the absorbing properties of M-type barium ferrite have changed significantly. This change is mainly due to the transition of trivalent $\mathrm{Fe}$ ions to divalent $\mathrm{Fe}$ ions, which affects the permeability of the material and the impedance matching, and broadens the absorbing effect at high frequencies [47-49].

Figure 7(a) shows the relationship between bandwidth and RL of BFTO- $x$ samples, and the maximum RL and bandwidth are listed in Table 3. For $x=0.2$, the greatest loss can be obtained at the thickness of $1.8 \mathrm{~mm}$, and the bandwidth can reach to $5.28 \mathrm{GHz}$ at $2 \mathrm{~mm}$ when RL is less than $-10 \mathrm{~dB}$, while the bandwidth of the other three components is about $3 \mathrm{GHz}$. 

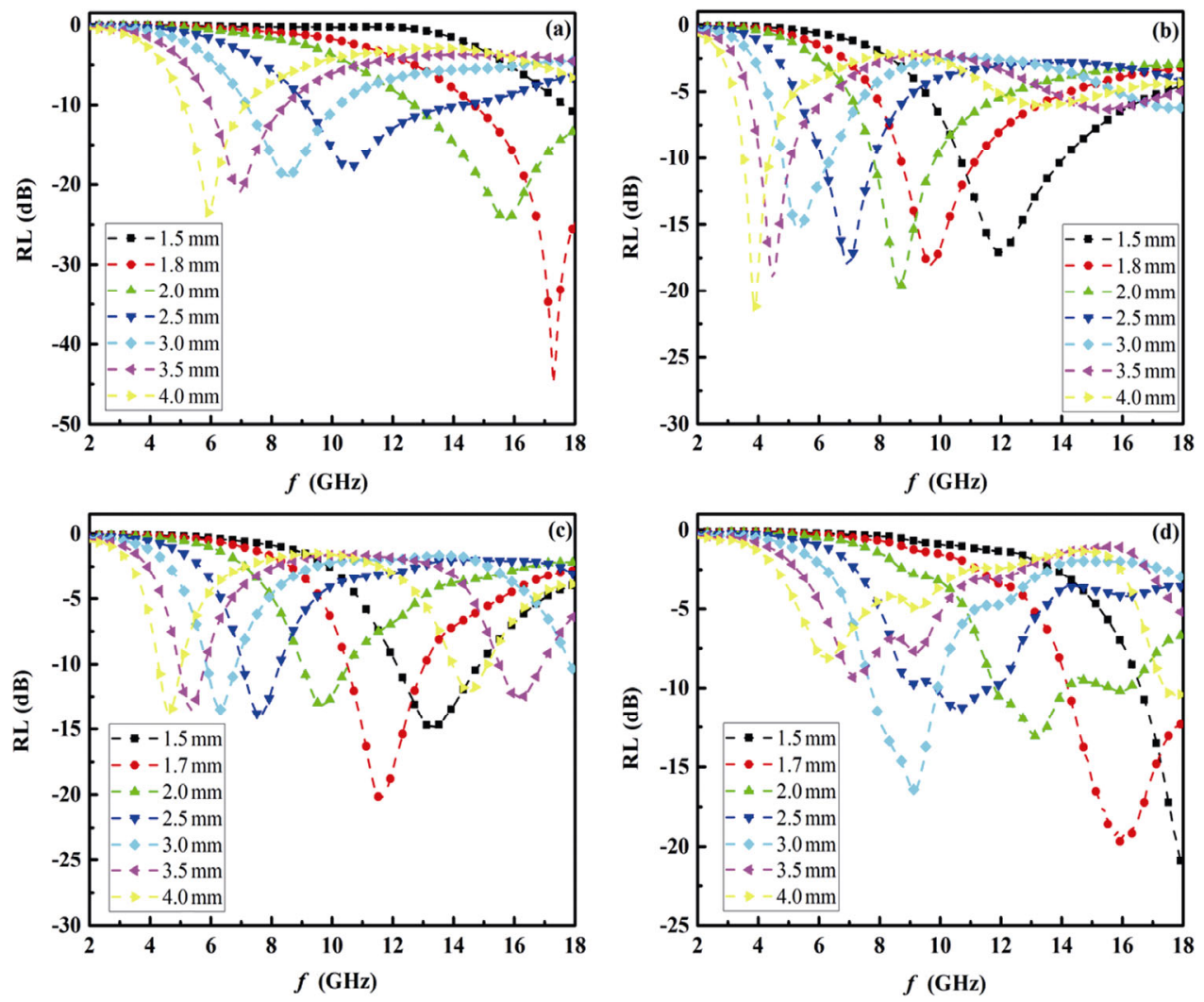

Fig. 5 RL curves of PVA mixed BFTO- $x$ ceramics in the frequency range of 2-18 GHz: (a) $x=0.2$, (b) $x=0.4$, (c) $x=0.6$, and (d) $x=0.8$.
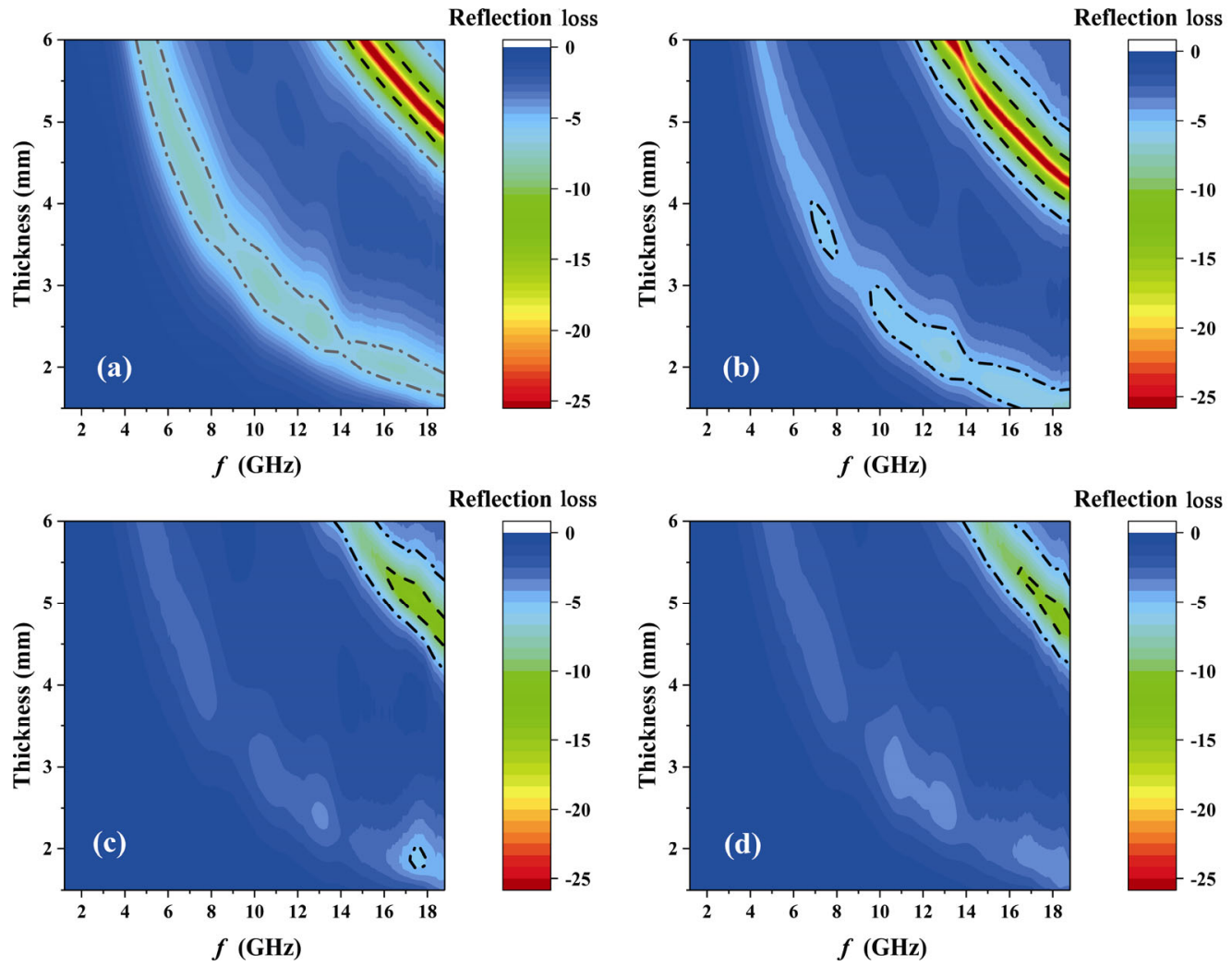

Fig. 6 3D RL contour plots of BFTO- $x$ ceramics: (a) $x=0.2$, (b) $x=0.4$, (c) $x=0.6$, and (d) $x=0.8$. 

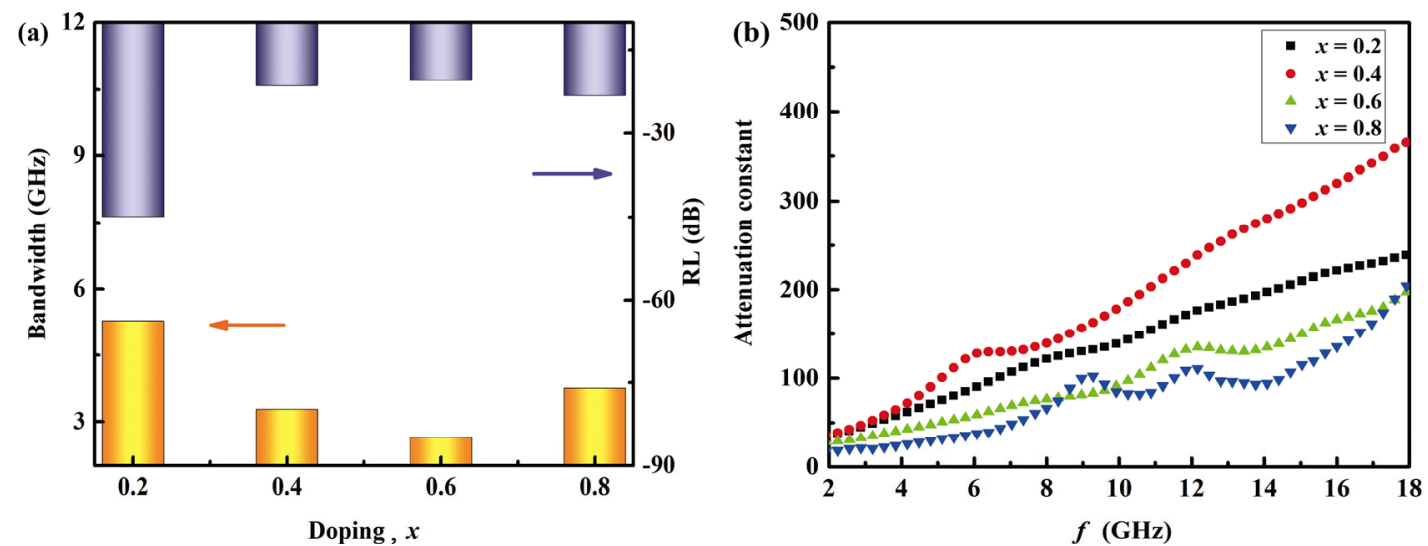

Fig. 7 (a) Maximum RL and the corresponding bandwidth over $-10 \mathrm{~dB}$ of each component and (b) attenuation constant of BFTO- $x$ ceramics.

Table 3 Maximum RL and corresponding bandwidth over $-10 \mathrm{~dB}$ of PVA-mixed BFTO- $x$ ceramics

\begin{tabular}{cccc}
\hline Component & Thickness (mm) & $\begin{array}{c}\text { Maximum } \\
\text { RL (dB); } \\
\text { position }(\mathrm{GHz})\end{array}$ & $\begin{array}{c}\text { Bandwidth } \\
<-10 \mathrm{~dB} \\
(\mathrm{GHz})\end{array}$ \\
\hline$x=0.2$ & 1.8 & $-44.93 ; 17.28$ & 3.28 \\
$x=0.4$ & 1.5 & $-17.1 ; 11.92$ & 3.28 \\
$x=0.6$ & 1.7 & $-20.3 ; 11.6$ & 2.48 \\
$x=0.8$ & 1.7 & $-19.6 ; 15.92$ & 3.76 \\
\hline
\end{tabular}

In the ion-doped barium ferrite ceramic, the strong absorbing ability originates from the high attenuation constant [50]. The attenuation constant is expressed by Eq. (2):

$$
\begin{aligned}
& \alpha= \\
& \left(\frac{\sqrt{2} \pi f}{c}\right) \sqrt{\left(\mu^{\prime \prime} \varepsilon^{\prime \prime}-\mu^{\prime} \varepsilon^{\prime}\right)+\sqrt{\left(\mu^{\prime \prime} \varepsilon^{\prime \prime}-\mu^{\prime} \varepsilon^{\prime}\right)^{2}+\left(\varepsilon^{\prime} \mu^{\prime \prime}+\varepsilon^{\prime \prime} \mu^{\prime}\right)^{2}}}
\end{aligned}
$$

where $f$ is the microwave frequency and $c$ is the velocity of light. According to Eq. (2), the attenuation constants of the four components of BFTO- $x$ ceramics can be calculated, as shown in Fig. 7(b). Within the measuring frequency range of $2-18 \mathrm{GHz}$, four components have a large attenuation constant, wherein the attenuation constant of $x=0.4$ component is the largest, 350. The variation trend of attenuation constants is similar to that of the imaginary part of magnetic permeability, and there is a double resonance peak in $x$ $=0.6$ and 0.8 components. Therefore, the dielectric constant and permeability are the two parameters that determine the microwave absorbing performance, and magnetic and dielectric loss is critical to improve the attenuation of materials to electromagnetic waves.

Besides, frequency modulation is also a standard for measuring the overall performance of absorbing materials. As can be seen from Figs. 4-7, the excellent frequency modulation can be obtained in the four components of BFTO- $x$ ceramics. RL peaks of the $x=$ 0.2 component are reduced from $\sim 17$ to $6 \mathrm{GHz}$ with varying thicknesses, and the frequency modulation range covers $69 \%$ of the measuring frequency range, enabling the control of a wide range of absorption frequencies. The frequency regulation ranges of $x=0.4$, 0.6 , and 0.8 components are 4-12, 5-18, and 6-18 GHz, respectively. Compared with Refs. [5,17,22], both the effective absorption bandwidth and the maximum loss of BFTO ceramics have been enhanced to a certain extent in this work. The maximum RL peaks of the four components also moved with the $\mathrm{Ti}^{4+}$ doping content, varying from $18 \mathrm{GHz}(x=0.8)$ to $4 \mathrm{GHz}(x=$ 0.4 ), which covers $81 \%$ of the investigated frequency. In conclusion, all of the four components of BFTO- $x$ ceramics show excellent frequency modulation ability.

\section{Conclusions}

The hexagonal sheet like $\mathrm{BaTi}_{x} \mathrm{Fe}_{12-x} \mathrm{O}_{19}(x=0.2,0.4$, $0.6,0.8)$ ceramics were synthesized by a modified sol-gel method. Through the refined analysis of neutron diffraction, $\mathrm{Ti}^{4+}$ tends to occupy the position $2 \mathrm{a}, 2 \mathrm{~b}$, and $12 \mathrm{k}$ of the structure. $M_{\mathrm{s}}$ decreases gradually with the increase of $\mathrm{Ti}^{4+}$ doping, but the change of the coercive force is complex under the synergy of the changed grain size and the magnetic crystal anisotropy field. The excellent microwave absorption performance $-44.9 \mathrm{~dB}$ with board bandwidth in the $x=0.2$ component can be attributed to the double resonance peak induced by high valent doping of $\mathrm{Ti}^{4+}$. Meanwhile, the RL peak position of the $x=0.6$ component can be 
adjusted from 18 to $5 \mathrm{GHz}$ and the remaining components cover up to $50 \%$ of the frequency adjusted range, which have a significant potential application value in microwave absorption field.

\section{Acknowledgements}

This work was supported by the National Natural Science Foundation of China (U2130110 and 51502054).

\section{Electronic Supplementary Material}

Supplementary material is available in the online version of this article at https://doi.org/10.1007/s40145-021-0529-3.

\section{References}

[1] Toneguzzo P, Viau G, Acher O, et al. Monodisperse ferromagnetic particles for microwave applications. $A d v$ Mater 1998, 10: 1032-1035.

[2] Singh C, Kaur H, Bindra Narang S, et al. Investigation of microwave absorption and DC electrical properties of $\mathrm{Mn}^{2+}$ and $\mathrm{Ti}^{4+}$ substituted $\mathrm{SrMn}_{x} \mathrm{Ti}_{x} \mathrm{Fe}_{(12-2 x)} \mathrm{O}_{19}$ ferrite. $J$ Alloys Compd 2016, 683: 302-307.

[3] Joshi R, Singh C, Singh J, et al. A study of microwave absorbing properties in $\mathrm{Co}-\mathrm{Gd}$ doped M-type $\mathrm{Ba}-\mathrm{Sr}$ hexaferrites prepared using ceramic method. J Mater Sci: Mater Electron 2017, 28: 11969-11978.

[4] Che R, Peng LM, Duan X, et al. Microwave absorption enhancement and complex permittivity and permeability of Fe encapsulated within carbon nanotubes. Adv Mater 2004, 16: 401-405.

[5] Singh J, Singh C, Kaur D, et al. Microwave absorbing characteristics in $\mathrm{Co}^{2+}$ and $\mathrm{Al}^{3+}$ substituted $\mathrm{Ba}_{0.5} \mathrm{Sr}_{0.5} \mathrm{Co}_{x} \mathrm{Al}_{x} \mathrm{Fe}_{12-2 x} \mathrm{O}_{19}$ hexagonal ferrite. J Mater Sci Mater Electron 2017, 28: 2377-2384.

[6] Liu CY, Zhang YT, Zhang YJ, et al. Multiple nature resonance behavior of $\mathrm{BaFe}_{x} \mathrm{TiO}_{19}$ controlled by $\mathrm{Fe} / \mathrm{Ba}$ ratio and its regulation on microwave absorption properties. J Alloys Compd 2019, 773: 730-738.

[7] Ding Y, Zhang L, Liao QL, et al. Electromagnetic wave absorption in reduced graphene oxide functionalized with $\mathrm{Fe}_{3} \mathrm{O}_{4} / \mathrm{Fe}$ nanorings. Nano Res 2016, 9: 2018-2025.

[8] Li J, Xu TT, Liu LL, et al. Microstructure, magnetic and low-frequency microwave absorption properties of doped Co-Ti hexagonal barium ferrite nanoparticles. Ceram Int 2021, 47: 19247-19253.

[9] Ye XL, Chen ZF, Ai SF, et al. Porous SiC/melamine-derived carbon foam frameworks with excellent electromagnetic wave absorbing capacity. J Adv Ceram 2019, 8: 479-488.

[10] Chiu SC, Yu HC, Li YY. High electromagnetic wave absorption performance of silicon carbide nanowires in the gigahertz range. J Phys Chem C 2010, 114: 1947-1952.

[11] Saini P, Arora M, Gupta G, et al. High permittivity polyaniline-barium titanate nanocomposites with excellent electromagnetic interference shielding response. Nanoscale 2013, 5: 4330.

[12] Jia JG, Liu CY, Ma N, et al. Exchange coupling controlled ferrite with dual magnetic resonance and broad frequency bandwidth in microwave absorption. Sci Technol Adv Mater 2013, 14: 045002.

[13] Liu CY, Fang G, Li Z, et al. Achieving impressive millimeter-wave absorption properties in $\mathrm{Nb}^{5+}$ doped Barium ferrite by simply controlling the sintering atmosphere. Mater Lett 2019, 244: 147-150.

[14] Pullar RC. Hexagonal ferrites: A review of the synthesis, properties and applications of hexaferrite ceramics. Prog Mater Sci 2012, 57: 1191-1334.

[15] Kaur R, Dhillon N, Singh C, et al. Microwave and electrical characterization of M-type $\mathrm{Ba}_{0.5} \mathrm{Sr}_{0.5} \mathrm{Co}_{x} \mathrm{Ru}_{x} \mathrm{Fe}_{(12-2 x)} \mathrm{O}_{19}$ hexaferrite for practical applications. Solid State Commun 2015, 201: 72-75.

[16] Singh C, Bindra Narang S, Koledintseva MY. Microwave absorption characteristics of substituted $\mathrm{Ba}_{0.5} \mathrm{Sr}_{0.5} \mathrm{M}_{x} \mathrm{Fe}_{(12-2 x)} \mathrm{O}_{19}\left(\mathrm{M}=\mathrm{Co}^{2+}-\mathrm{Zr}^{4+}\right.$ and $\left.\mathrm{Co}^{2+}-\mathrm{Ti}^{4+}\right)$ sintered ferrite at X-band. Microw Opt Technol Lett 2012, 54: 1661-1665.

[17] Nikmanesh H, Hoghoghifard S, Hadi-Sichani B. Study of the structural, magnetic, and microwave absorption properties of the simultaneous substitution of several cations in the barium hexaferrite structure. J Alloys Compd 2019, 775: 1101-1108.

[18] Nikmanesh H, Moradi M, Kameli P, et al. Effects of annealing temperature on exchange spring behavior of Barium hexaferrite/nickel zinc ferrite nanocomposites. $J$ Electron Mater 2017, 46: 5933-5941.

[19] Liu CY, Zhang YJ, Jia JG, et al. Multi-susceptibile single-phased ceramics with both considerable magnetic and dielectric properties by selectively doping. Sci Rep 2015, 5: 9498.

[20] Zhivulin VE, Trofimov EA, Zaitseva OV, et al. Flux single crystal growth of $\mathrm{BaFe}_{12-x} \mathrm{Ti}_{x} \mathrm{O}_{19}$ with titanium gradient. Crystals 2020, 10: 264.

[21] Gupta S, Upadhyay SK, Siruguri V, et al. Observation of magnetoelastic and magnetoelectric coupling in Sc doped $\mathrm{BaFe}_{12} \mathrm{O}_{19}$ due to spin-glass-like phase. J Phys Condens Matter 2019, 31: 295701.

[22] Trukhanov SV, Trukhanov AV, Kostishyn VG, et al. Magnetic, dielectric and microwave properties of the $\mathrm{BaFe}_{12-x} \mathrm{Ga}_{x} \mathrm{O}_{19} \quad(x \leqslant 1.2)$ solid solutions at room temperature. J Magn Magn Mater 2017, 442: 300-310.

[23] Xu J, Lu QL, Lin JF, et al. Enhanced Ferro-/piezoelectric properties of tape-casting-derived $\mathrm{Er}^{3+}$-doped $\mathrm{Ba}_{0.85} \mathrm{Ca}_{0.15} \mathrm{Ti}_{0.9} \mathrm{Zr}_{0.1} \mathrm{O}_{3}$ optoelectronic thick films. $J A d v$ Ceram 2020, 9: 693-702.

[24] Kumar Y, Yadav KL, Shah J, et al. Investigation of magnetoelectric effect in lead free $\mathrm{K}_{0.5} \mathrm{Na}_{0.5} \mathrm{NbO}_{3}-$ $\mathrm{BaFe}_{12} \mathrm{O}_{19}$ novel composite system. $J$ Adv Ceram 2019, 8: 333-344.

[25] Li J, He S, Shi KZ, et al. Coexistence of broad-bandwidth and strong microwave absorption in $\mathrm{Co}^{2+}-\mathrm{Zr}^{4+}$ co-doped barium ferrite ceramics. Ceram Int 2018, 44: 6953-6958. 
[26] Tsutaoka T, Koga N. Magnetic phase transitions in substituted Barium ferrites $\mathrm{BaFe}_{12-x}\left(\mathrm{Ti}_{0.5} \mathrm{Co}_{0.5}\right)_{x} \mathrm{O}_{19}(x=$ 0-5). J Magn Magn Mater 2013, 325: 36-41.

[27] Liu CY, Zhang YJ, Tang Y, et al. The tunable magnetic and microwave absorption properties of the $\mathrm{Nb}^{5+}-\mathrm{Ni}^{2+}$ co-doped M-type Barium ferrite. J Mater Chem C 2017, 5: 3461-3472.

[28] Liu CY, Chen YJ, Yue YY, et al. Formation of $\mathrm{BaFe}_{12-x} \mathrm{Nb}_{x} \mathrm{O}_{19}$ and its high electromagnetic wave absorption properties in millimeter wave frequency range. J Am Ceram Soc 2017, 100: 3999-4010.

[29] Nikmanesh H, Hoghoghifard S, Hadi-Sichani B, et al. Erbium-chromium substituted strontium hexaferrite particles: Characterization of the physical and Ku-band microwave absorption properties. Mater Sci Eng: B 2020, 262: 114796.

[30] Rodríguez-Carvajal J. Recent advances in magnetic structure determination by neutron powder diffraction. Phys B: Condens Matter 1993, 192: 55-69.

[31] Wills AS. A new protocol for the determination of magnetic structures using simulated annealing and representational analysis (SARAh). Phys B: Condens Matter 2000, 276-278: 680-681.

[32] Shao Y, Huang FZ, Xu XY, et al. Multi-susceptible single-phase $\mathrm{BaAl}_{x} \mathrm{Fe}_{12-x} \mathrm{O}_{19}$ ceramics with both improved magnetic and ferroelectric properties. Appl Phys Lett 2019, 114: 242902.

[33] Watanabe K, Kawabe J. Growth and characterization of minute $\mathrm{BaFe}_{12-2 x} \mathrm{Ti}_{x} \mathrm{Co}_{x} \mathrm{O}_{19}$ crystals from high-temperature solution. J Mater Chem 1997, 7: 1797-1800.

[34] Vinnik DA, Zherebtsov DA, Mashkovtseva LS, et al. Ti-substituted $\mathrm{BaFe}_{12} \mathrm{O}_{19}$ single crystal growth and characterization. Cryst Growth Des 2014, 14: 5834-5839.

[35] Gupta T, Chauhan CC, Kagdi AR, et al. Investigation on structural, hysteresis, Mössbauer properties and electrical parameters of lightly Erbium substituted X-type $\mathrm{Ba}_{2} \mathrm{Co}_{2} \mathrm{Er}_{x} \mathrm{Fe}_{28-x} \mathrm{O}_{46}$ hexaferrites. Ceram Int 2020, 46: 8209-8226.

[36] Cheng YK, Ren XH. Permeability and electromagnetic wave absorption properties of sintered Barium hexaferrites with substitution of $\mathrm{Co}^{2+}-\mathrm{Zr}^{4+}$. J Mater Sci: Mater Electron 2016, 27: 772-775.

[37] Singh C, Narang SB, Hudiara IS, et al. Hysteresis analysis of $\mathrm{Co}-\mathrm{Ti}$ substituted M-type $\mathrm{Ba}-\mathrm{Sr}$ hexagonal ferrite. Mater Lett 2009, 63: 1921-1924.

[38] Narang SB, Singh C, Bai Y, et al. Microstructure, hysteresis and microwave absorption analysis of $\mathrm{Ba}_{(1-x)} \mathrm{Sr}_{x} \mathrm{Fe}_{12} \mathrm{O}_{19}$ ferrite. Mater Chem Phys 2008, 111: 225-231.

[39] Nikmanesh H, Eshraghi M, Karimi S. Cation distribution, magnetic and structural properties of $\mathrm{CoCr}_{x} \mathrm{Fe}_{2-x} \mathrm{O}_{4}$ : Effect of calcination temperature and chromium substitution. $J$ Magn Magn Mater 2019, 471: 294-303.

[40] Singh C, Bindra-Narang S, Hudiara IS, et al. The effect of $\mathrm{Co}$ and $\mathrm{Zr}$ substitution on de magnetic properties of $\mathrm{Ba}-\mathrm{Sr}$ ferrite. J Alloys Compd 2008, 464: 429-433.
[41] Alam RS, Moradi M, Nikmanesh H. Influence of multiwalled carbon nanotubes (MWCNTs) volume percentage on the magnetic and microwave absorbing properties of $\mathrm{BaMg}_{0.5} \mathrm{Co}_{0.5} \mathrm{TiFe}_{10} \mathrm{O}_{19} / \mathrm{MWCNTs}$ nanocomposites. Mater Res Bull 2016, 73: 261-267.

[42] Nikmanesh H, Moradi M, Bordbar GH, et al. Synthesis of multi-walled carbon nanotube/doped Barium hexaferrite nanocomposites: An investigation of structural, magnetic and microwave absorption properties. Ceram Int 2016, 42: 14342-14349.

[43] Zhang HW, Rong $\mathrm{CB}, \mathrm{Du} \mathrm{XB}$, et al. Investigation on the coercivity and remanence of single-phase nanocrystalline permanent magnets by micromagnetic finite-element method. J Magn Magn Mater 2004, 278: 127-137.

[44] Gairola SP, Verma V, Singh A, et al. Modified composition of Barium ferrite to act as a microwave absorber in X-band frequencies. Solid State Commun 2010, 150: 147-151.

[45] Liu JR, Itoh M, Machida KI. Electromagnetic wave absorption properties of $\mathrm{Fe}_{1-x} \mathrm{Co}_{x} / \mathrm{Y}_{2} \mathrm{O}_{3}(x=0.33,0.5,0.67)$ nanocomposites in gigahertz range. $J$ Alloys Compd 2005, 389: $265-269$.

[46] Watts CM, Liu XL, Padilla WJ. Metamaterial electromagnetic wave absorbers. Adv Mater 2012, 24 : OP98-OP120.

[47] Liu CY, Xu QK, Tang Y, et al. $\mathrm{Zr}^{4+}$ doping-controlled permittivity and permeability of $\mathrm{BaFe}_{12-} \mathrm{Zr}_{x} \mathrm{O}_{19}$ and the extraordinary EM absorption power in the millimeter wavelength frequency range. $J$ Mater Chem C 2016, 4: 9532-9543.

[48] Singh J, Singh C, Kaur D, et al. Tunable microwave absorption in Co-Al substituted M-type $\mathrm{Ba}-\mathrm{Sr}$ hexagonal ferrite. Mater Des 2016, 110: 749-761.

[49] Kaur H, Marwaha A, Singh C, et al. Investigation of structural, hysteresis and electromagnetic parameters for microwave absorption application in doped $\mathrm{Ba}-\mathrm{Sr}$ hexagonal ferrites at X-band. J Alloys Compd 2019, 806: 1220-1229.

[50] Huo J, Wang L, Yu HJ. Polymeric nanocomposites for electromagnetic wave absorption. J Mater Sci 2009, 44: 3917-3927.

Open Access This article is licensed under a Creative Commons Attribution 4.0 International License, which permits use, sharing, adaptation, distribution and reproduction in any medium or format, as long as you give appropriate credit to the original author(s) and the source, provide a link to the Creative Commons licence, and indicate if changes were made.

The images or other third party material in this article are included in the article's Creative Commons licence, unless indicated otherwise in a credit line to the material. If material is not included in the article's Creative Commons licence and your intended use is not permitted by statutory regulation or exceeds the permitted use, you will need to obtain permission directly from the copyright holder.

To view a copy of this licence, visit http://creativecommons. org/licenses/by/4.0/. 